\title{
RELATIONSHIP BETWEEN LEPTIN HORMONE LEVELS AND RABBIT DOES PERFORMANCE DURING PREGNANCY PERIOD
}

\author{
G. Ashour ${ }^{1 *}$; Samah M. Abdel-Rahman ${ }^{2}$ and Noha M. Abdel-Azeem ${ }^{2}$ \\ 1-Animal Production Department, Faculty of Agriculture, Cairo University, Giza, Egypt, 2-Animal Production \\ Research Institute, Agricultural Research Center, Dokki, Egypt \\ *Corresponding author: gashour57@yahoo.com
}

A total number of 30primiparous New Zealand White (NZW) pregnant rabbit. Does aged between 5-6 months and their average BW was 3098.15 $\pm 20.24 \mathrm{~g}$ were used.

The results showed that, leptin levels increased slightly during gestation days, reached to the highest value $(2.91 \mathrm{ng} / \mathrm{ml})$ at day 28 of pregnancy and then declined at delivery day. Furthermore, leptin levels negatively correlated with GST, $\mathrm{H}_{2} \mathrm{O}_{2}$ and MDA. Both $\mathrm{H}_{2} \mathrm{O}_{2}$ and MDA were at the lower levels day 28 of pregnancy when leptin recorded its highest level $(2.91 \mathrm{ng} / \mathrm{ml})$. This clear that, leptin may play an important role in the system of antioxidant and free radicals. Further studies are urgently needed, to study this relationship deeply in rabbits to clarify its interaction with the antioxidant system. Blood proteins (TP, Alb and A/G, except Glb) were associated positively with leptin levels. This indicates that, leptin may interfere with blood proteins metabolism. In general, blood proteins tended to be increased during pregnancy days. Furthermore, leptin correlated positively with plasma TG, which declined insignificantly during gestation days, and recorded its lower value $(135.11 \mathrm{mg} / \mathrm{dl})$ at day 28 of pregnancy. Additionally, leptin also was in a positive relationship with BUN levels, which were higher than normal range at days 13 and 21 of pregnancy. Afterwards, significantly declined at day 28 and insignificantly at delivery day. Meanwhile, CR levels correlated negatively with leptin levels. All values of CR were within the normal range, and its lower value $(0.80 \mathrm{mg} / \mathrm{dl})$ was at day 21 of gestation and was significantly differ than its values at day 28 and kindling day. The liver enzymes (AST and ALT) were in a positive relationship with leptin levels. These enzymes declined during gestation days recorded its lower values (25.00 and 20.50 U/L) for AST and ALT at kindling day and day 28 of pregnancy, respectively. Also, body weight of dam, litter weights and size were positively associated with leptin levels, because leptin play an important role in regulating BW by controlling the mass of adipose tissue. Additionally the results showed a negative relationship between leptin levels and milk yield, MF, ML and milk ash. In contrast, MP, NTS and MSNF were associated positively with leptin levels. 